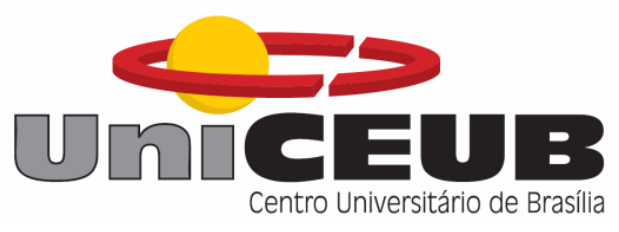

CENTRO UNIVERSITÁRIO DE BRASÍLIA - UniCEUB FACULDADE DE CIÊNCIAS DA EDUCAÇÃO E DA SAÚDE FACES

\author{
PROGRAMA DE INICIAÇÃO CIENTíFICA
}

JOÃO CARLOS MORAIS E SILVA

RAFAEL DE JESUS MOREIRA

\begin{abstract}
Pesquisa de Rickettsia, Erlichia e Anaplasma em ectoparasitas coletados em cães no Distrito Federal, no ano de 2015
\end{abstract}

BRASÍLIA-DF

2016 


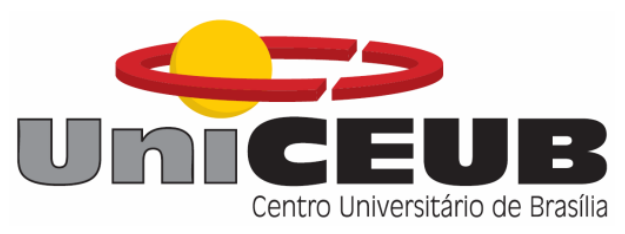

JOÃO CARLOS MORAIS E SIVA

RAFAEL DE JESUS MOREIRRA

\section{Pesquisa de Rickettsia, Erlichia e Anaplasma em ectoparasitas coletados em cães no Distrito Federal, no ano de 2015}

Relatório final de pesquisa de Iniciação

Científica apresentado à Assessoria de Pós-Graduação e Pesquisa pela Faculdade de Ciências da Educação e da Saúde FACES.

Orientação: Bruno Silva Milagres. 


\section{AGRADECIMENTO}

Primeiramente gostaria de agradecer a todos aqueles amigos e familiares que torcerem para que esse projeto desse certo.

Gostaria de agradecer ao meu grande mestre, o orientador Bruno Silva Milagres que com sua ajuda, sabedoria, dedicação e paciência foi de extrema importância, proporcionando a devida orientação para a pesquisa. Ao parceiro de pesquisa Rafael de Jesus Moura, que contribuiu diretamente para a concretização da pesquisa com sua ajuda e dedicação.

Um agradecimento ao CNPq pelo intuito de acreditar em novos pesquisadores, dando, assim, todo auxílio e suporte para que o projeto existisse e ao Cetro Universitário de Brasília, UniCEUB, pelo grande apoio, compreensão e dedicação aos jovens pesquisadores que precisavam sanar dúvidas e questionamentos.

No mais, agradecer a todos aqueles que contribuíram direta e indiretamente para que a pesquisa fosse iniciada e finalizada com êxito. À todos vocês meu eterno agradecimento. 
"A ciência trabalha no limite entre conhecimento e ignorância. Não temos medo de admitir o que não sabemos, não há vergonha nisso. A única vergonha seria fingir que sabemos de tudo." (Neil deGrasse Tyson) 


\section{RESUMO}

Carrapatos são ectoparasitas obrigatórios onde 10\% das espécies infectam 0 homem e outros mamíferos por agentes etimológicos, bactérias, vírus ou protozoários, causadores de doenças hematoparasitoses, tais como: Rickettsia, que se caracteriza por infecções por bactérias gran-negativas, do grupo da Febre Maculosa; erliquiose, que é causada pela espécie Ehrilichia canis, uma bactéria pertencente à família Rickettsiaceae, de gênero Ehrchilia, que se configura como uma das principais infecções caninas, tendo como o principal vetor o carrapato vermelho ou marrom da espécie Rhipicephalus sanguíneus. A Anaplasma platys é uma espécie de bactéria do gênero Anaplasma, pertencente da família Anaplasmatacea, de ordem das Rickettsiales, que acomete cães que estiveram em contato com carrapato. A identificação dessas bactérias se faz através da análise da biologia molecular dos carrapatos por meio da técnica de reação em cadeia de polimerase (PCR), para que se chegue a um diagnóstico preciso. $O$ objetivo desta pesquisa foi determinar a presença dessas enfermidades em cães das cidades satélites do Distrito Federal (DF) no período de 2015 a 2016, além da epidemiologia descritiva dos casos de febre maculosa no Brasil. A coleta foi realizada por meio da extração de 62 ectoparasitas presentes em 10 cães previamente selecionados, em seguida foi feita a identificação dos carrapatos conforme sexo, espécie e estágio de desenvolvimento, onde foram devidamente agrupados em pools, de acordo com o sistema de classificação estabelecida pelos integrantes desta pesquisa. Foram realizados testes prévios de PCR utilizando baixas concentrações (20ng e 50ng) dos controles positivos para comprovar que o PCR funcionaria para amostras contendo baixas concentrações de DNA (Ácido desoxirribonucleico). Devido ao tamanho dos espécimes coletados, várias amostras tiveram concentrações muito baixas de DNA que prejudicaram e/ou não permitiram a realização dos PCRs, na qual foram catalogados e analisados 20 amostras dos 62 indivíduos entre machos e fêmeas com estágios de desenvolvimento variando entre ninfas, larvas e adultos com potencial concentração de material biológico, todos sendo da espécie Rhipicephalus sanguineus. Todas as amostras analisadas tiveram resultados negativos para Rickettsia, Erlichia e Anaplasma. Com base em revisão 
bibliográfica nos anos de 2015 foram confirmados 90 casos de febre maculosa, sendo que $62 \%$ dos casos se encontram em São Paulo (SP), tendo uma letalidade de $44.4 \%$, com estimativa de $68,8 \%$ dos casos sendo do sexo masculino com faixa etária mais acometida entre 40 a 59 anos. A predominância dessas bactérias se dá em zonas rurais, sendo menos presentes em áreas urbanas no decorrer de 2015. Com relação ao Distrito Federal não foram relatados casos no ano de 2015, porém é de extrema importância a realização de novas pesquisas com estudos mais aprofundados, para que se possa fazer um maior levantamento de dados de coleta, além de uma maior sensibilização dos profissionais da saúde para este agravo.

Palavras-chaves: Carrapatos. Zoonoses. Epidemiologia. 


\section{SUMÁRIO}

LISTA DE SÍMBOLOS, SIGLAS E ABREVIATURAS..................................

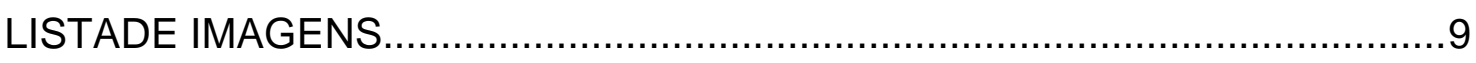

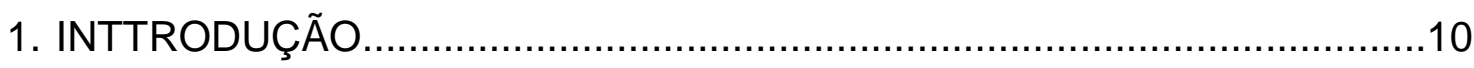

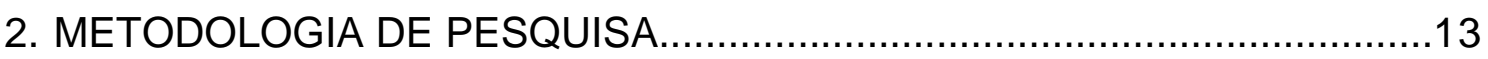

2.1 ESTUDO EPIDEMIOLÓGICO..........................................................13

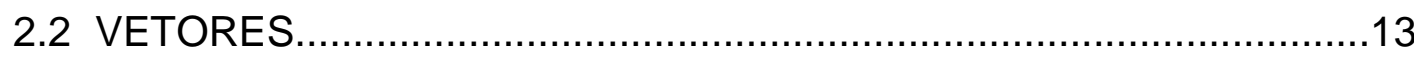

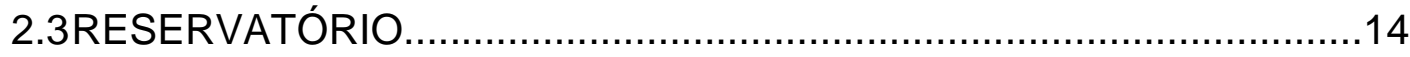

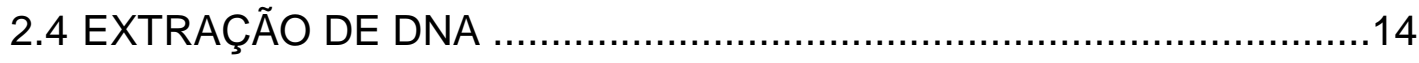

2.5 REAÇÃO EM CADEIA DA POLIMERASE - (PCR) …........................ 15

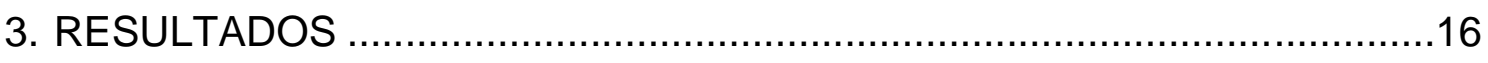

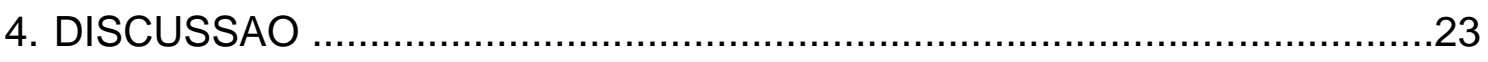

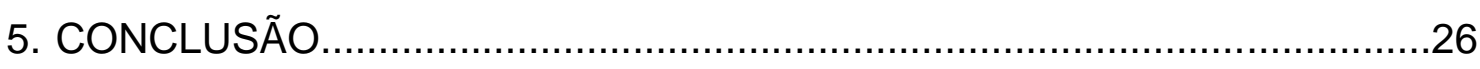

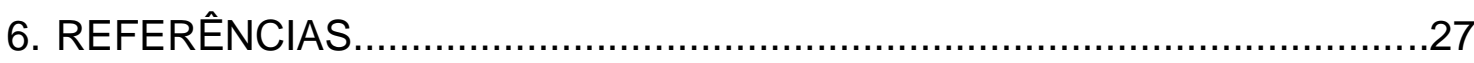




\section{LISTA DE SÍMBOLOS, SIGLAS E ABREVIATURAS}

DF Distrito Federal - Brasil.

DNA Ácido desoxirribonucleico

FMB $\quad$ Febre Maculosa Brasileira

PCR Reação em Cadeia de Polimerase

SINAN Sistema de Informação de Agravos de Notificação 


\section{LISTADE IMAGENS E GRÁFICOS}

Quadro 1: Concentração de DNA em amostras coletadas dos carrapatos.

Figura 1: Gel de Agarose para avaliar o PCR das amostras de DNA extraídos dos carrapatos.

Figura 2: Testes do PCR utilizando baixas concentrações de DNA (20ng e 50ng).

Gráfico 1: Número de Casos de Febre Maculosa notificados e confirmados no ano de 2014 a 2015

Gráfico 2: Número de casos de Febre Maculosa no Brasil no ano de 2014 a $\underline{2015}$

Gráfico 3: Porcentagem média do $n^{\circ}$ de casos de Febre Maculos Por Zonas infectadas entre os anos de 2014-2015.

Gráfico 4: Porcentagem média de $n^{\circ}$ de casos de Febre Maculosa no Brasil por Gênero nos anos de 2014 a 2015.

Gráfico 5: Número de casos de Febre Maculosa no Brasil por faixa etária entre $\underline{2014 \text { a } 2015}$

Gráfico 6: Número de óbitos por Febre Maculosa no Brasil avaliados no ano de $\underline{2014 \text { a } 2015 .}$ 


\section{INTRODUÇÃO}

Carrapatos são artrópodes hematófagos, ectoparasitas obrigatórios não permanentes e de extrema importância na transmissão de enfermidades zoonóticas por meio de bioagentes que podem causar complicações clinicas ao seu hospedeiro (VIEIRA et al., 2002). A distribuição dessa enfermidade é de nível mundial, sendo mais presentes em zonas urbanas e rurais, porém, devido as condições climáticas do Brasil, o desenvolvimento de infestações desses artrópodes é favorecido (SOUZA et al., 2009). Carrapatos são parasitas de diversos animais, tais como anfíbios, répteis, aves e mamíferos (LUZ et al., 2013). Porém se percebe uma maior infestação em mamíferos domésticos como bois, cavalos, cães e o homem, ficando presos à pele do animal parasitado por semanas, se alimentando de seu fluido biológico (DASTAS-TORRES, 2009), abandonando-o em seguida e parasitando outros diferentes animais ao longe de seu ciclo de vida, na qual é dessa forma que esses ectoparasitas promovem um prejuízo econômico estimado no brasil em $\mathrm{R} \$ 2$ bilhões no setor do agronegócio (GRISIS et al., 2002).

Outro problema observado está na infestação desses artrópodes em cães domésticos, onde são considerados uma das maiores preocupações à saúde do cachorro devido as graves enfermidades hematoparasitoses trazidas ao animal por agentes etimológicos como, bactérias, vírus ou protozoários provenientes da picada do carrapato, e consequentemente transmitida ao homem (KANTOS et al, 2014). Nos últimos anos, tem se confirmado um melhoria em volta dos estudos relacionados a doenças irradiadas por aproximadamente $10 \%$ das espécies de carrapatos no Brasil. Estudos mais recentes demonstram que as principais doenças endêmicas em certas regiões do país são as Rickettsia, Ehrilichia canis, uma bactéria pertencente à família Rickettsiaceae, de gênero Ehrilichia e Anaplasma (RAMOS et al, 2010;. SPOLIDORIO et al, 2011 ;. VIEIRA et al, 2013 ;. COSTA-JÚNIOR et al, 2012 ;. SILVA et al, 2012 ;. DEMONER et al, 2013).

O grupo das riquetsioses é constituído por parasitas intracelulares obrigatórios que se caracteriza por infecções de bactérias gram-negativas, do grupo da Febre Maculosa (MILAGRES et al., 2013). A Rickettsiales é uma ordem 
normalmente dividida em dois grupos: $O$ grupo tifo e o grupo das Febres Maculosas. O grupo tifo manifesta uma das mais letais infecções para o homem, com cerca de $60 \%$ de casos de óbito sem tratamento, e estando limitada a três principais espécies a Rickettsia prowazekii, uma bactéria intracelular obrigatório, do tipo gram-negativa que infecta e cresce no citosol das células dos seus hospedeiros; A Rickettsia typhi outra enfermidade causado pelo agentes etimológicos gram-negativas, causadora do tifo murino e com estágio de transmissão alternados em dois ciclos, sendo o primeiro em ratos selvagens e o segundo em animais domésticos, tais como gatos e cães; A espécie Rickettsia canada é uma bactéria gram-negativa que é singular de carrapatos (CHAREONVIRIYAPHAP et al, 2014;. GAZI et al, 2013;. MILAGRES et al, 2010;. NOGUERAS et al, 2013;. WOOD et al, 2012).

O grupo das febres maculosas são constituídas por inúmeras espécies de carrapatos, onde as principais endêmicas no brasil são: Amblyomma aureolatum e Amblyomma cajennense que se caracteriza por um ectoparasita vetor da bactéria Rickettsia rickettsii, microrganismo intracelular obrigatório, agente da febre maculosa e febre das montanhas do norte (termo usado em diagnóstico de pacientes viventes na américa do norte), que ocasiona fase febril aguda de gravidade variável, o que torna essa enfermidade de maior importância médica no Brasil (COUTO et al, 2015; MILAGRES et al, 2010).

A febre maculosa brasileira $(F M B)$, é a febre mais mortal do mundo dentre o grupo da febre maculosa onde se tem evidenciados e divulgados 1146 casos, com cerca de 411 mortes confirmadas (40,5\% de taxa de mortalidade) na região sudeste do Brasil, nos anos de 1985-2012 (KRAWCZAK et al, 2014). A identificação dessas bactérias se faz através da análise da biologia molecular dos carrapatos, e por meio da técnica de reação em cadeia de polimerase (PCR). Embora o sintomas da febre maculosa brasileira (FMB) sejam característicos, ela é facilmente confundida com outros tipos de febres provocadas por bactérias gram-negativas, tornando a análise laboratorial indispensável para que se chegue a um diagnóstico preciso (COSTA et al, 2015).

Como citado a cima, outras patologias associadas a picada do carrapato é a Ehrilichia e Anaplasma. A Erliquiose é causada por uma bactéria gram- 
negativa intracelular obrigatória que infectam animais vertebrados, onde se verifica umamaior infestação em mamíferos, tais como gatos, ovelhas, bovinos, equinos cães e homem (ARRAIS, 2013. O gênero Ehrlichia pertence à família das Rickettsiaceae e compreende, atualmente, cinco espécies válidas: Ehrlichia canis, E. chaffeensis, E. ewingii, E. muris e E. ruminatium, sendo essas erliquioses causadoras de doenças distintas (AGUIAR, 2007).

A Erliquiose canina é uma bactéria intracitoplasmática e pertence à ordem Rickettsiales, proveniente de ectoparasitas, sendo seu principal vetor o Rhipicephalus sanguineus, vulgarmente conhecido com carrapato marrom, e que mais acomete cães domésticos. Essa doença é caracterizada pela redução dos elementos celulares sanguíneos obrigatórios dos leucócitos, provocando a doença mundialmente conhecida como Tickborne canina. Considera-se essa doença amplamente distribuída por todo Brasil, com aproximadamente $40 \%$ dos casos registrados em cães (ARRAIS, 2013;. OTRANTO et al 2008;. STANNECK et al, 2012;. NICHOLSON et al, 2010;.STANNECK \& FOURIE, 2013).

A Anaplasmataceae está inserida à uma familia compostas por agententes patogênicas e nao-patogênicas, conhecidas como comensais e multualisticos. A Anaplasmose é uma das hematoparasitoses promovida pelas bactérias, de caráter zoonotico, intracelulares obrigatórios que infectam neutrófilo, hemácias, células granulócíticas sadias e, até mesmo, hematopoiéticas de seus hospedeiros, tais como canídeos, bovinos e equídeos, podendo, também, infectar humanos através da picada do carrapato do gênero Ixodes (GOMES, 2008;. RIKIHISA, 2010).

O objetivo deste trabalho foi determinar a presença de Rickettsia, Erlichia e Anaplasma em ectoparasitas coletados de cães nas cidades satélites do Distrito Federal (DF) no período de 2015, além da epidemiologia descritiva, por meio de revisões bibliográficas, dos casos de febre maculosa, eliquiose e anaplasma no Brasil. 


\section{METODOLOGIA DE PESQUISA}

\subsection{ESTUDOS EPIDEMIOLÓGICOS}

Foi feita uma pesquisa descritiva em cima de revisões bibliográficas em volta das doenças acometidas em carrapatos, seus principais vetores, meios de infecção e transmissão, além dos diagnóstico clínicos sobre Febre maculosa, Erliquiose e Anaplasma que estão acometidas nos ectoparasitas estudados ao longo da pesquisa.

Se fez necessário o levantamento de casos relatados dessas doenças, afim de computar dados, por meio de pesquisas em livros, artigos e semiários, retrospectivas, que foram de extrema importância para o andamento da pesquisa.

A computação de dados se fez através dos programas de computadores Microsoft Word -2013, Microsoft Exel, e, o aplicativo para armazenamentos de dados OneDrive.

\subsection{VETORES.}

$\mathrm{Na}$ indagação do estudo dos ectoparasitas, nos baseamos em acervos bibliográficos atualizados sobre os principais vetores das enfermidades abordadas nesta pesquisa. A coleto dos ectoparasitas foi realizado por meio de busca ativa em cachorros domésticos e de vida livre, de raça pura e mestiços e em Petshop das cidades satélites do Distrito Federal (DF) como Taguatinga, Guará, Samambaia e Lago sul. Os parasitas foram acondicionados em recipiente plástico de armazenamento de material biológico de $150 \mathrm{ml}$, em meio a álcool $70 \%$, para melhor preservação das amostragens biológicas, ande foram separados por gênero, sexo, tamanho e estágio de desenvolvimento, onde foram devidamente agrupados em pools, de acordo com o sistema de classificação usando chave dicotômica e pictórica descrita por Aragão \& Fonseca (1961), onde foram enviadas para o Laboratório de Parasitologia e Epidemiologia do Departamento de Bioquímica e Biologia molecular da Universidade Federal de Viçosa para se fazerem análises da biologia molecular dos carrapatos para se averiguar a presença da bactéria Rickettsia rickettsii, Erlichiose canis ou 
Anaplasma, por meio da técnica de reação em cadeia de polimerase (PCR), onde foram testados previamente utilizando baixas concentrações (20ng e 50ng) dos controles positivos para comprovar que o PCR funcionaria para amostras contendo baixas concentrações de DNA (Ácido desoxirribonucleico). Os primers utilizados nos PCRs foram: Rickettsia - CS 239 / CS 1069; Hepatozoon - HepF / HepR; Ehrlichia - DSB330 / DSB 728.

\subsection{RESERVATÓRIOS}

O estudo dos reservatório e animais sentinelas das riquetisioses, erliquias e anaplasma, foram baseadas em pesquisas bibliográficas e acervos eletrônicos atualizados da literatura através de artigos, seminários e livros dentro da área de saúde pública, epidemiologia e parasitologia sobre o papel do cão na promoção do ciclo de vida dos carrapatos e na importância desse intermediário na disseminação das enfermidades presentes nessa pesquisa. Foi aplicada uma ficha cadastral para cada cachorro das cidades satélites do DF, com as seguintes observações: quantidade de carrapatos coletados em cada animal, raça, endereço, nome do cachorro e data da última aplicação de algum pesticida.

\subsection{EXTRAÇÃO DE DNA}

A extração de DNA dos ectoparasitos foi realizada de acordo com o protocolo descrito por Billings e colaboradores (1998). Cada pool de ectoparasitas foi lavado com etanol $70 \%$ em quantidade suficiente para cobrir os ectoparasitos durante 15 minutos. Em seguida, foram lavados em tampão fosfato (PBS pH 7,2) por 5 minutos (duas vezes). Foram adicionados $200 \mu \mathrm{L}$ do tampão fosfato para maceração dos vetores, os quais foram triturados com auxílio de uma ponteira de polietileno. No mesmo tubo foram acrescentados SDS $10 \% \mathrm{v} / \mathrm{v}$ e Proteinase $\mathrm{K}(20 \mathrm{mg} / \mathrm{mL})$ para uma concentração final de $1 \%$ e, em seguida, incubados em banho-maria a 55ㄷ overnigth. À amostra digerida, acrescentouse $200 \mu \mathrm{L}$ de fenol:clorofórmio (1:1), submetendo-a a centrifugação (12000 x g, 2 minutos). A fase aquosa foi retirada e o sobrenadante transferido para um tubo novo. Esse procedimento foi repetido 6 vezes. Ao sedimento, foram adicionados 
$200 \mu \mathrm{L}$ de clorofórmio, seguido de uma nova centrifugação. O sobrenadante foi novamente transferido para um tubo estéril, sendo acrescido $40 \mu \mathrm{L}$ de $\mathrm{NaCl}$ 2,5M, $200 \mu \mathrm{L}$ de clorofórmio e dois volumes de etanol $100 \%$ gelado. Os tubos foram armazenados a $-20^{\circ} \mathrm{C}$ overnight. Em seguida, as amostras foram centrifugadas a $12000 \times \mathrm{g}$ sob temperatura de $4^{\circ} \mathrm{C}$ por 15 minutos. Ao sedimento restante, foram adicionados $300 \mu \mathrm{L}$ de etanol $70 \%$ e novamente centrifugados a $13000 \mathrm{rpm}$ sob temperatura de $4^{\circ} \mathrm{C}$ por 15 minutos, para ressuspender o DNA previamente precipitado. Por fim, o sobrenadante foi descartado e o precipitado resuspendido em $100 \mu \mathrm{L}$ de água estéril, destilada e deionizada e posteriormente, armazenados a $-4^{\circ} \mathrm{C}$. Desse material foram retirados $20 \mu \mathrm{L}$ para quantificação em espectofotômetro $(260 \mathrm{~nm})$, sendo todas as amostras ajustadas para concentração de $50 \mathrm{ng} / \mu \mathrm{L}$.

\subsection{REAÇÃO EM CADEIA DA POLIMERASE - (PCR)}

Pesquisa de DNA de Rickettsia spp. através da amplificação de um fragmento de 549 pares de bases do gene citrato sintase $(\mathrm{g} / \mathrm{t} A)$, detectado em todas as espécies de Rickettsia, utilizando-se um par de oligonucleotídeos iniciadores, denominados CS1069 (CAGGGTCTTCGTGCATTTCTT) e CS239 (GCTCTTCTCATCCTATGGCTATTAT) referente ao gene citrato sintase com um tamanho de fragmento aproximado de 549 pares de base. Para os genes de hepatozoa foram utilizados HepF (5 -ATACATGAGCAAAATCTCAAC-3 ) and HepR (5 -CTTATTATTCCATGCTGCAG-3 ) (Inokuma et al., 2002).

A PCR de ehrlichia foi realizada conforme Doyle et al. (2005), visando à amplificação de fragmento de 409 pares de base $(\mathrm{pb})$ do gene dsb de Ehrlichia spp., utilizando-se os iniciadores Dsb-330 (5'-GAT GAT GTC TGA AGA TAT GAA ACA AAT-3') e Dsb-728 (CTG CTC GTC TAT TTT ACT TCT TAA AGT-3').

Os dados da PCR realizada são os seguintes. Mix com composição de água (10,32uL), tampão 10X com MgCl2 (15mM) (2uL), dNTP (2mM) (4uL), primer CS239 (10uM) (0,8uL), primer CS1069 (10uM) (0,8uL), KapaTaq (U/uL) $(0,1 \mathrm{uL})$. 


\section{RESULTADOS}

Depois dos métodos adotados para a classificação dos carrapatos, foi possível se obter a identificação total de 62 ectoparasitas enviados para análise, não sendo possível a identificação de 42 exemplares devido à baixa concentração de matéria biológico, no caso, de Ácido Desoxirribonucleico (DNA) o que prejudicou ou impossibilitou a devida análise da biologia molecular desses exemplares por meio de PCRs. Se obteve a análise ideal de 20 espécimes do total, onde desses foi obtido: 2 ninfas fêmeas pertencentes ao grupo R2-amostra 1; 1 ninfa macho pertencente ao grupo R2- amostra 2; 2 larvas pertencentes ao grupo R2- amostra 3; 4 machos adultos pertencentes ao grupo R1- amostra 4; 1 fêmea adulta pertencente ao grupo R1- amostra 5; 2 fêmeas adultas pertencentes ao grupo R3- amostra 6; 1 macho adulto pertencente ao grupo R4amostra 7; 2 Fêmeas adultas pertencentes ao grupo A- amostra 8; 1 ninfa fêmea pertencente ao grupo A- amostra 9; 4 ninfas fêmeas pertencentes ao grupo Bamostra 10. Todos os exemplares foram identificados como sendo da espécie Rhipicephalus sanguineus. O quadro a seguir mostra a quantidade de material biológico dos exemplares que foram analisados.

Quadro 1: Concentração de DNA em amostras coletadas dos carrapatos.

\begin{tabular}{|c|c|}
\hline Amostras Obtidas & Concentração de DNA \\
\hline Amostra 1 & $29,65 \mathrm{ng} / \mu \mathrm{L}$ \\
\hline Amostra 2 & $116,3 \mathrm{ng} / \mu \mathrm{L}$ \\
\hline Amostra 3 & $12,95 \mathrm{ng} / \mu \mathrm{L}$ \\
\hline Amostra 4 & $159,7 \mathrm{ng} / \mu \mathrm{L}$ \\
\hline Amostra 5 & $57,3 \mathrm{ng} / \mu \mathrm{L}$ \\
\hline Amostra 6 & $809,95 \mathrm{ng} / \mu \mathrm{L}$ \\
\hline Amostra 7 & $70,2 \mathrm{ng} / \mu \mathrm{L}$ \\
\hline Amostra 8 & $4,5 \mathrm{ng} / \mu \mathrm{L}$ \\
\hline Amostra 9 & $19,7 \mathrm{ng} / \mu \mathrm{L}$ \\
\hline Amostra 10 & $13,35 \mathrm{ng} / \mu \mathrm{L}$ \\
\hline
\end{tabular}


A coleta foi prejudicada pelo período de chuva que se instalou nos últimos meses das coletas, diminuindo assim o número de parasitas coletados, outro empecilho foi a falta de informação por parte dos donos dos animais, em relação a Febre Maculosa, onde muitos desconheciam a existência de tal enfermidade, evitando assim que realiza-se a procura pelo parasita no cachorro, pois achavam que seus animais seriam recolhidos. Outra dificuldade estava relacionada à coleta dos ectoparasitas em animais de vida livre, uma vez que esses animais não permitiram a devida aproximação e contato por parte dos integrantes da pesquisa, impossibilitando a devida coleta de carrapatos.

As análises em PCR (Reação em Cadeia de Polimerase) e a Eletroforese em Gel de Agarose, realizada em todos os 20 carrapatos com quantidade mínima de material biológico, tiveram resultado negativo para a bactéria Rickettsia ricketsii, Ehrlichia canis e Anaplasma platys. A figura 1 demostram os testes feitos para cada amostra em Gel de Agarose dos PCRs.

Figura 1: Gel de Agarose para avaliar o PCR das amostras de DNA extraídos dos carrapatos.

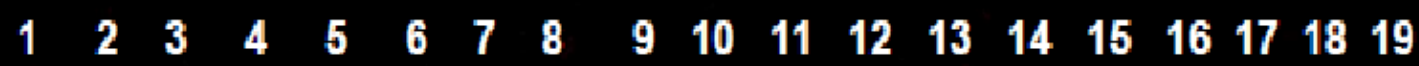

Fonte: Laboratório de Parasitologia e Epidemiologia do Departamento de Bioquímica e Biologia Molecular, Universidade de Viçosa - MG. 
1- peso molecular

2- amostra 4 para Rickettsia

3- amostra 5 para Rickettsia

4- amostra 6 para Rickettsia

5- amostra 7 para Rickettsia

6- controle positivo para Rickettsia

7- controle negativo para Rickettsia

8- vazio

9- amostra 4 para Erlichia

10- amostra 5 para Erlichia
11- amostra 6 para Erlichia

12- amostra 7 para Erlichia

13- vazio

14- amostra 4 para Hepatozzon

15- amostra 5 para Hepatozzon

16- amostra 6 para Hepatozzon

17- amostra 7 para Hepatozzon

18- vazio

19- vazio|

Fonte: Laboratório de Parasitologia e Epidemiologia do Departamento de Bioquímica e Biologia Molecular, Universidade de Viçosa - MG.

A figura 2 esboça os testes de controle positivo realizados em PCRs nas baixas concentrações de $20 \mathrm{ng}$ e 50ng.

Figura 2: Testes do PCR utilizando baixas concentrações de DNA (20ng e 50ng).

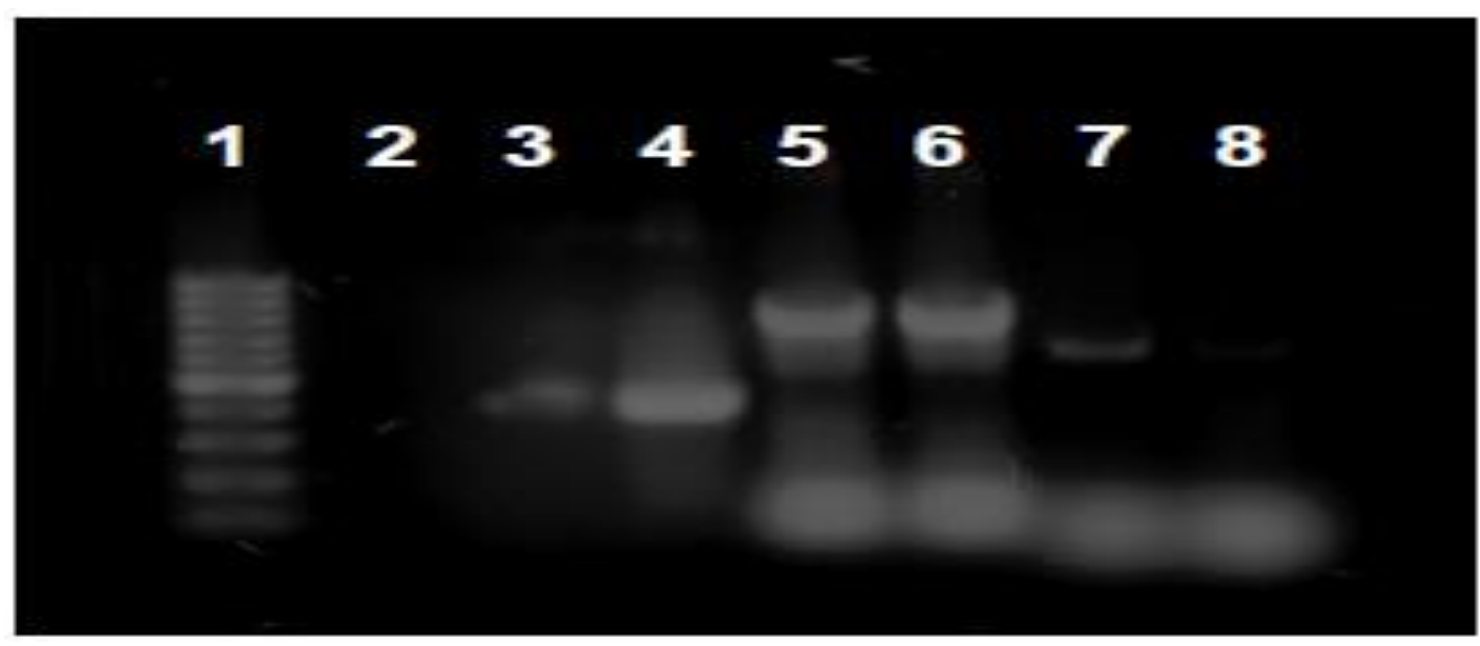

1- marcador molecular

2- controle negativo Rickettsia

3- controle positivo Rickettsia com $50 \mathrm{ng}$

4- controle positivo Rickettsia com $20 \mathrm{ng}$

5- controle positivo Hepatozoon com $50 \mathrm{ng}$

6- controle positivo Hepatozzon com $20 \mathrm{ng}$

7- controle positivo Erlichia com $50 \mathrm{ng}$

8- controle positivo Erlichia com $20 \mathrm{ng}$

Fonte: Laboratório de Parasitologia e Epidemiologia do Departamento de Bioquímica e Biologia Molecular, Universidade de Viçosa - MG. 
Os anos de 2014 e 2015 foram registrados um total de 269 casos de Febre Maculosa confirmados acometendo em toda região do Brasil, onde foram confirmados 138 casos só no estado de São Paulo, como mostra o gráfico 1. Pode se verificar através do gráfico 2 , dados comparativos de casos notificados de febre maculos nas regiões do país, onde se percebe que a região Sudeste acomete 190 casos confirmados de uma somatória de 269 .

Gráfico 1: Número de Casos de Febre Maculosa notificados e confirmados no ano de 2014 a 2015.

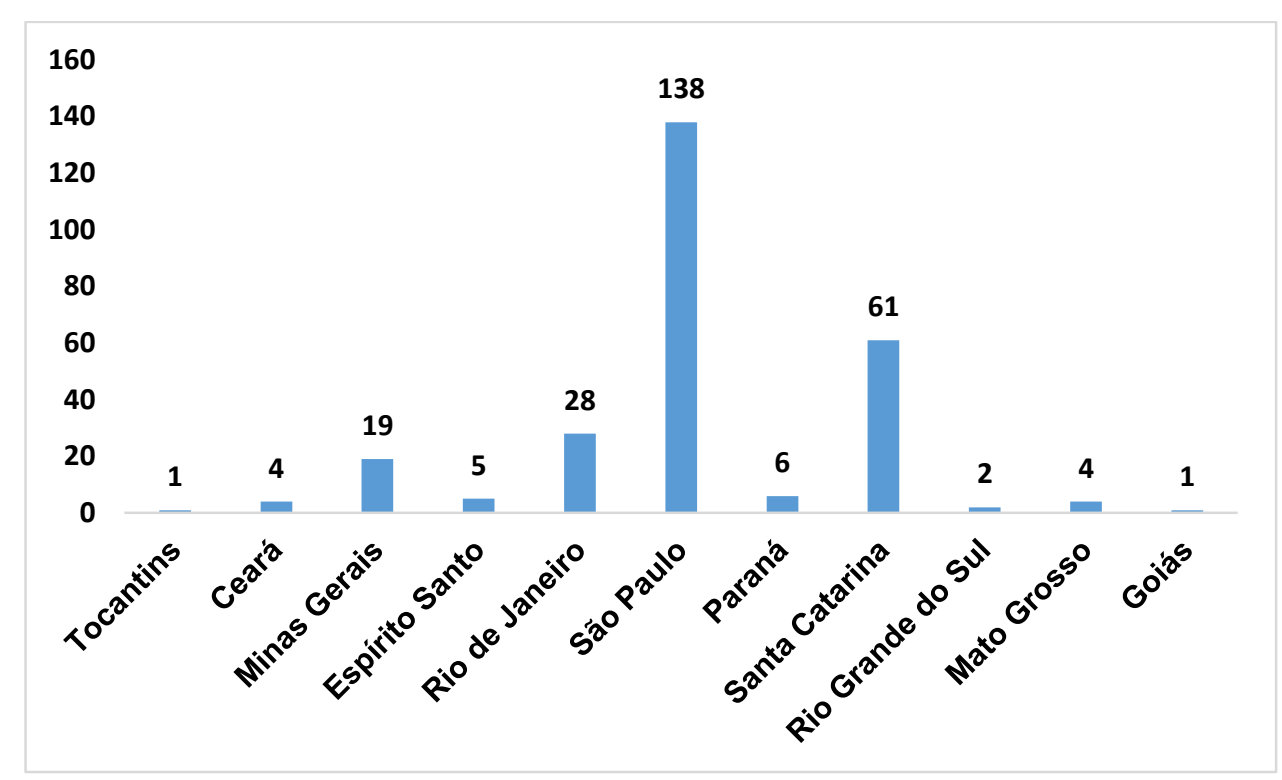

Fonte: Ministério da Saúde/SVS - Sistema de Informação de Agravos de Notificação - SINAN Net, 2016.

Gráfico 2: Número de casos de Febre Maculosa no Brasil no ano de 2014 a 2015

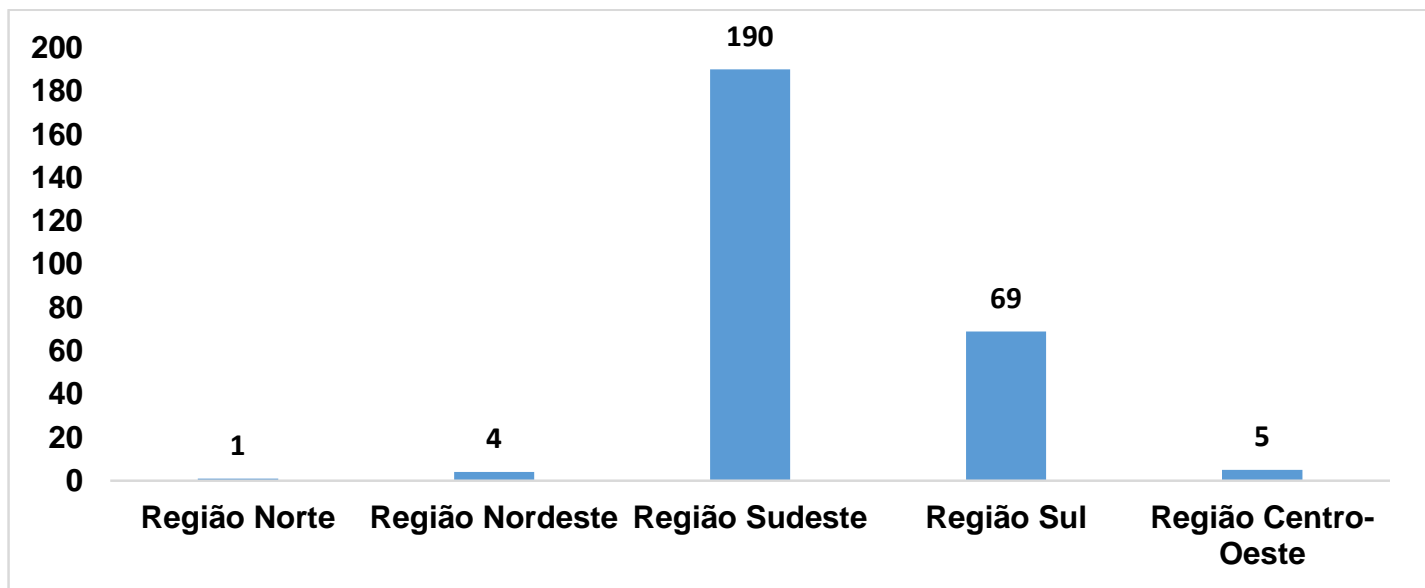

Fonte: Ministério da Saúde/SVS - Sistema de Informação de Agravos de Notificação - SINAN Net, 2016. 
Diante do número de casos registrados nos anos estudados de 2014 a 2015 mostrados pelos gráfico 3, observou-se uma média da prevalência maior de $47 \%$ dos casos em zona rurais devido à grande facilidade de proliferação de carrapatos nessas áreas, seguido de $35 \%$ dos casos registrados desses anos estudados em zonas urbanas, e 18\% dos casos para áreas de transição entre rural e urbana

Gráfico 3: Porcentagem média do $n^{\circ}$ de casos de Febre Maculos Por Zonas infectadas entre os anos de 2014-2015.

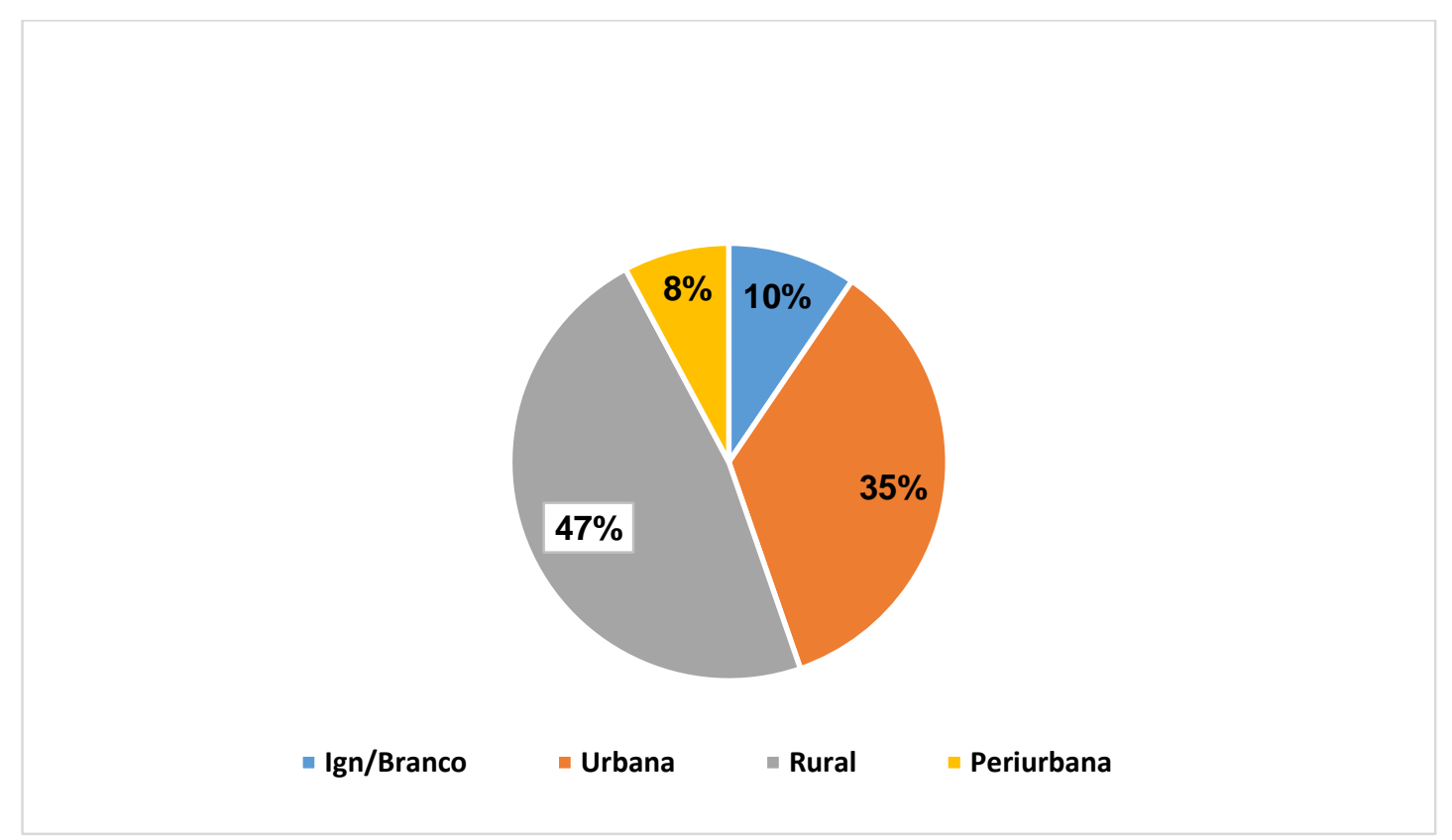

Fonte: Ministério da Saúde/SVS - Sistema de Informação de Agravos de Notificação - SINAN Net, 2016.

Estudos preliminares feitos nos anos de 2014 a 2015, como mostra no gráfico 4, indica um maior acometimento da Febre Maculosa em homens entre 54 a 64 anos, como mostra o gráfico 5, com 193 casos registrados com média de $72 \%$, contra 76 casos registrados de mulheres entre 21 a 30 anos, gráfico 5 , com média de $28 \%$. Somado a maior porcentagem de casos em zonas rurais, se conclui que a doença estudada acomete mais os homens de devido ao contato diretos dos trabalhadores rurais com os carrapatos potencialmente infectados com esse patógeno. 
Gráfico 4: Porcentagem média de $n^{\circ}$ de casos de Febre Maculosa no Brasil por Gênero nos anos de 2014 a 2015.

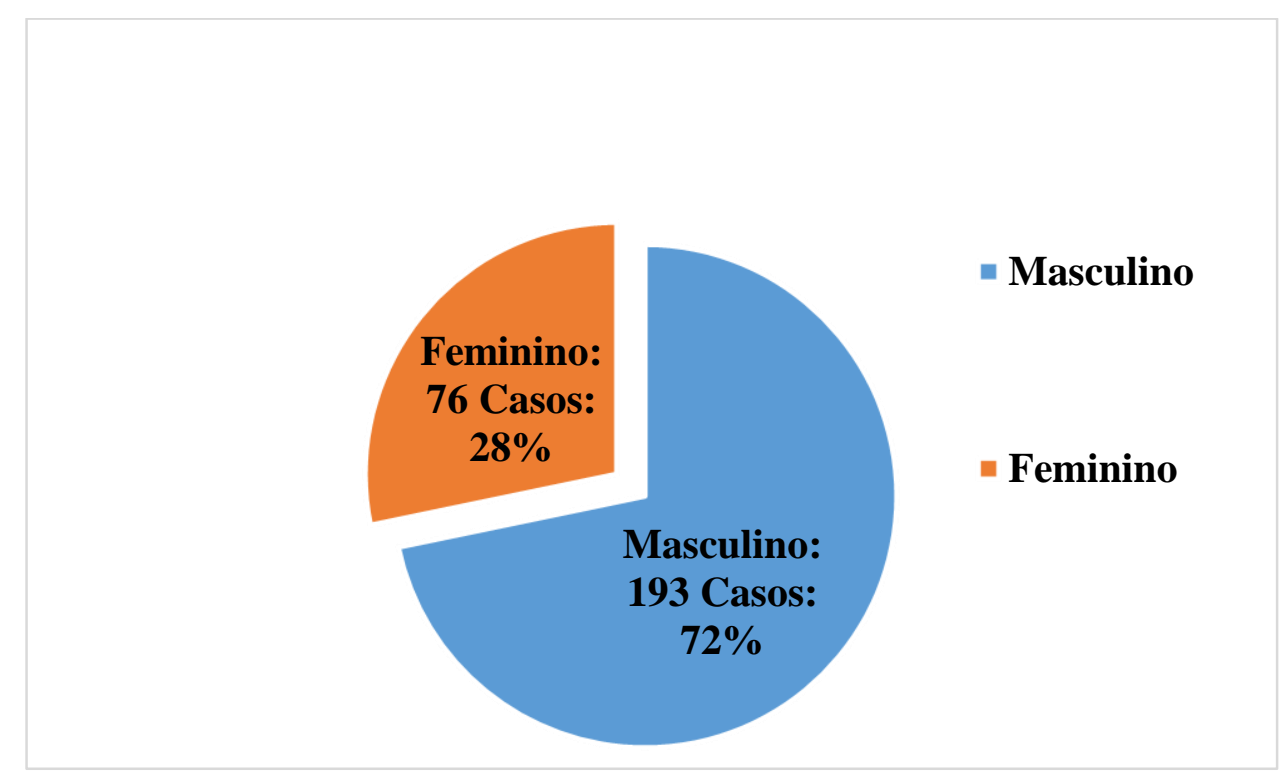

Fonte: Ministério da Saúde/SVS - Sistema de Informação de Agravos de Notificação - SINAN Net.

Gráfico 5: Número de casos de Febre Maculosa no Brasil por faixa etária entre 2014 a 2015

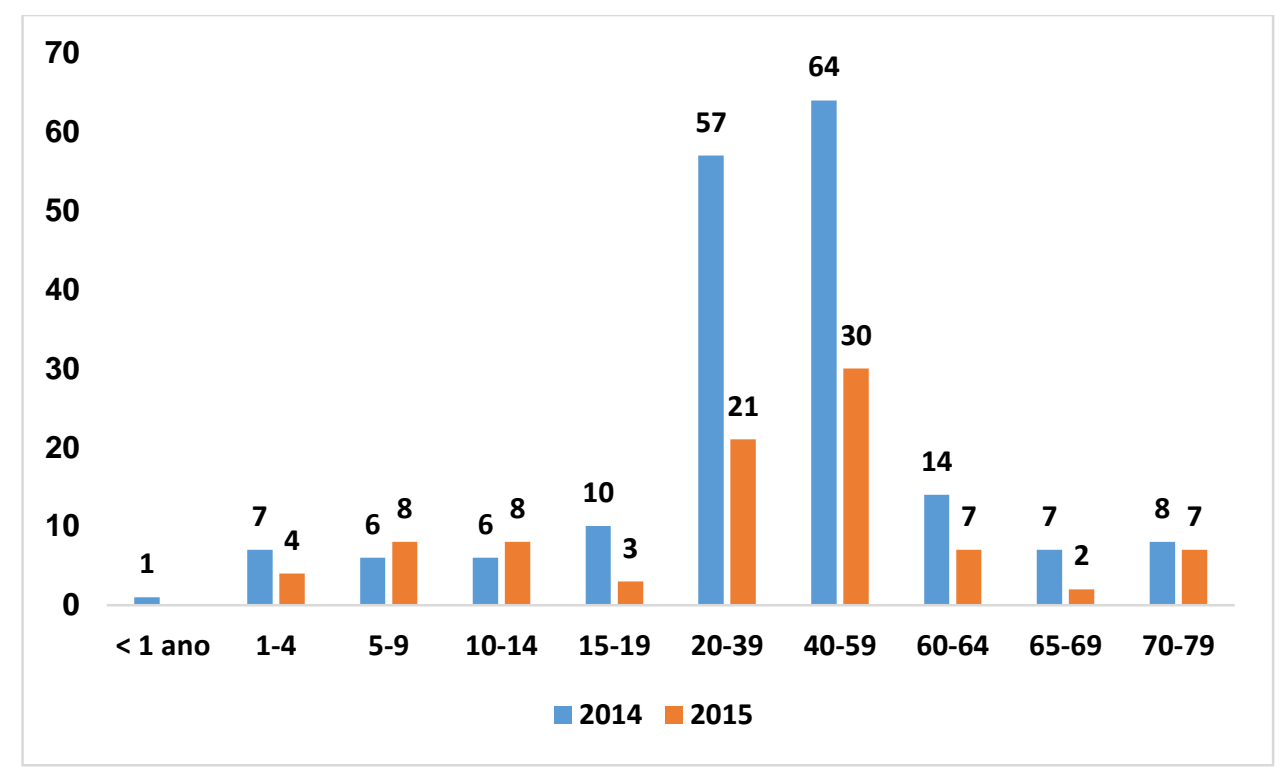

Fonte: Ministério da Saúde/SVS - Sistema de Informação de Agravos de Notificação - SINAN Net, 2016.

Também foi avaliado o número de óbitos por Febre Maculosa nos anos de 2014 a 2015 com uma letalidade de 46,8 \%, sendo 99 óbitos confirmados só 
no estado de São Paulo, somado a outros valores, e tendo um total de 118 óbitos confirmados distribuído nos principais estados do país, como mostra o gráfico 6 . Gráfico 6: Número de óbitos por Febre Maculosa no Brasil avaliados no ano de 2014 a 2015.

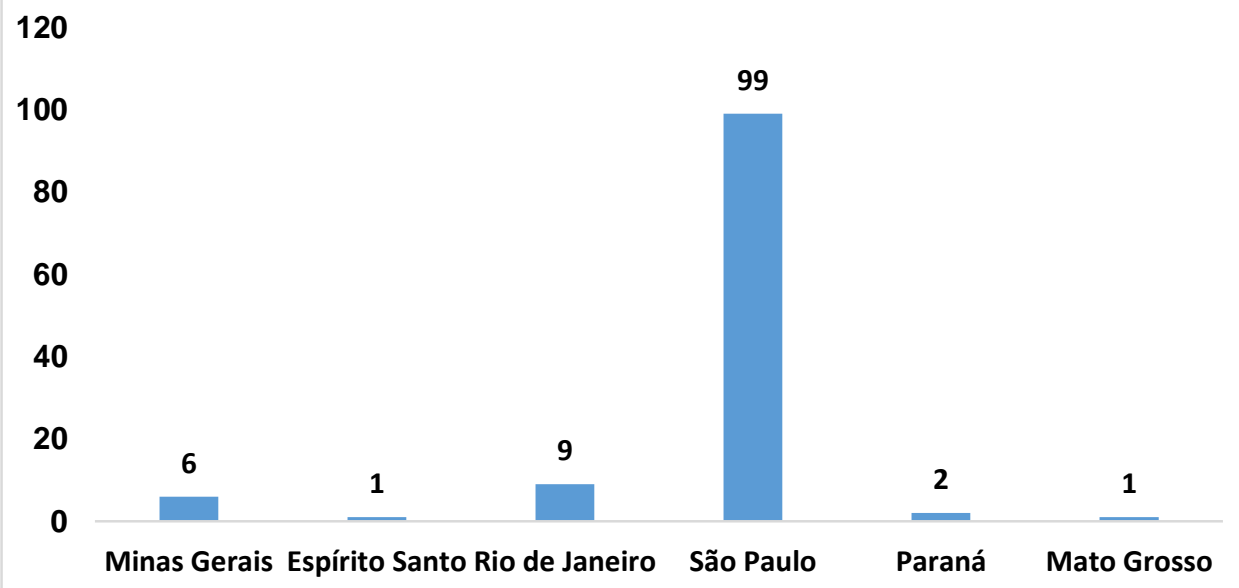

Fonte: Ministério da Saúde/SVS - Sistema de Informação de Agravos de Notificação - SINAN Net, 2016. 


\section{DISCUSSÃO}

Estudos apontaram que o cão é um animal reservatório de extrema importância para a vigilância epidemiológica, devido a sua proximidade com o homem, logo, o controle nos números de parasitas, dificulta o contato com os agentes causadores de diversas patógenos, além de prejudicar o seu clico vida (FORTES, F. S.; BIONDO, A. W.; MOLENTO, M. B, 2011). Carrapatos são ectoparasitas obrigatórios, não permanentes e hematófagos estritos. Sua distribuição é mundial com predominância em regiões zoogeográficas, parasitando uma ampla espécies de vertebrados. Durante as coletas dos ectoparasitas nas residências de zonas urbanas nas cidades satélites do DF, foi percebido que a quantidade de ectoparasitas é relativamente pequena, o que pode ser explicado por conta dos métodos de controle, os quais são voltados para áreas de circulação do cão seja dentro de casa ou fora, tendo em vista que a parcela pequena de parasitas se hospede no animal, onde promoverá o desenvolvimento do carrapato iniciado pela faze de ovo, três activas-larva, ninfa e adultos (NUNCIO, 2014; LABRUNA, 2004).

Para que o programa de controle e tratamento tenha sua plena eficiência contra infestações do agente patogênico $R$. sanguineus, as aplicações de acaricidas deve ser feito em locais onde os carrapatos estão acometidos, seja em moradas dos cães, gramas, frestas de paredes. Em casos de terrenos arenoso, se faz necessária a retirada da camada superficial de areia, expondo assim as teleógenas ao produto acaricida possibilitando que $95 \%$ dos ectoparasitas sejam atingidos (LABRUNA, 2001; MILAGRES, 2010)

A Febre Maculosa Brasileira (FMB) ocorre de forma esporádica em diversas regiões do Brasil, com destaque para as regiões Sudeste e Sul, onde são notificados os maiores índices de casos confirmados. A FMB está presente em áreas urbanas, periubanas e rurais, com ênfase para a última, onde encontrase um maior número de casos. (MOLIETERNO, 2009). Tal enfermidade acomete majoritariamente a faixa etária entre 40 e 59 anos economicamente ativa principalmente o sexo masculino (SILVA et al, 2014), que tenha frequentado áreas de vegetação arbustiva, matas, corpos d'água e pessoas que exercem atividades rurais, ou que possam ter tido contato com animais como: equinos, 
bovinos, capivaras, ovelhas, cães e gatos, ou que tenha entrado em contato direto com próprio ectoparasita (PINTER et al, 2011). Devido a dinâmica sazonal do carrapato Amblyomma cajennense principal vetor da bactéria Rickettsia rickettsii, ocorrem infecções durante todo o ano, entretanto, entre os meses de julho a dezembro nota-se um crescimento no número de caso, principalmente no mês de outubro, no qual as larvas e ninfas, que diferente do carrapato adulto, além da difícil identificação pelo seu menor porte, possuem uma picada menos dolorosa, aumentando assim o período de parasitismo e de chances de transmissão do patógeno (MOLITERNO, 2009).

Nos anos de 2007 a 2015 foi observada um aumento nos números de casos suspeitos de Febre Maculos, entretanto, os números de casos confirmados apresentam elevada variação (como mostrado no gráfico 1). Se observou nos anos de estudo que as altas taxas de letalidade registradas na região Sudeste do país, mais precisamente na região de São Paulo, porém casos de incidência mais altas estão sento registrados na região Sul, em Santa Catarina, além de serem registrados casos preocupantes da presença da espécies de Rickettsia encontradas em carrapatos nas regiões de Mato Grosso do Sul e Rondônia, onde se percebe a expansão da Febre Maculosa no Brasil (LABRUNA, 2005; ALMEIDA, 2013; OLIVEIRA et al, 2016).

Foram relatados casos de óbitos no sul do Brasil, nos ares de transição nas régios do estado de São Paulo, indicando uma possível ocorrência de Rickettsia rickettsii, onde esses registros indicam uma preocupação à saúde publica, sendo preciso destacar a necessidade de mais investigações sobre as astirpes que ocorrem nessas regioes (OLIVEIRA, 2015).

O diagnóstico nos primeiros dias é dificultado devido os sintomas se apresentarem de forma sistêmica e inespecífica, similares a diversas doenças comuns a população como: dengue, malária, pneumonia causada por Mycoplasma pneumoniae, salmonelose e hepatite viral (BRASIL, 2005). O principal achado clínico para diagnóstico da FMB é o exantema maculopapular, surge entre o terceiro e quinto dia da doença, com predomínio nos membros inferiores, palmas das mãos e plantas dos pés (VRANJAC, 2003). Entretanto, não deve-se ater somente a tal achado, uma vez que o mesmo pode ser 
confundido com outras doenças exantemáticas como: sífilis, meningococcemia, enteroviroses e infecções por Streptobacillus moniliformis (LEMOS et al, 2014).

Os sinais clínicos em seres humanos surgem por volta do $2^{\circ}$ ao $14^{\circ}$ dia após o contato com o agente etiológico da FMB (NOGUEIRA et al, 2005). Os sintomas surgem de forma súbita apresentando febre alta, calafrios, cefaleia, dores musculares, articulares, ósseas e prostração (MELLES et al, 1992). Grande parte dos hospedeiros da bactéria Rickettsia rickettsii não apresentam sintomas, entretanto, cachorros infectados podem manifestar dores abdominais, febre alta, anorexial, petéquias na boca, letargia, nistagmo e conjuntivite (FONTES, F. S.; BIONDO, A. W.; MOLENTO, M. B, 2011). 


\section{CONCLUSÃO}

A partir dos resultados obtidos, conclui-se que, nos anos de 2014 a 2015, o número de casos notificados de Febre Maculosa oscilou, mas mostrou-se baixo nos anos de estudo, porém a taxa de mortalidade foi considerada alta se fizermos uma proporção com o número de casos confirmados com o número de óbitos, dados que mantém o Ministério da Saúde em alerta. Evidenciou-se que o gênero mais acometido pela FMB foi o masculino e que a zona infectada que apresentou o maior número de casos foi a rural, por apresentar potencial contato direto com ectoparasitas infectados, seguida de zonas urbanas nos anos de estudo desta pesquisa. Estudos apontaram que o cão é um animal reservatório de extrema importância para a vigilância epidemiológica, uma vez que seu controle implica na diminuição dessas enfermidades fazendo com o que 0 contato com o homem e esses parasitas seja reduzida.

Entretanto, a melhor forma de controlar os casos é, claramente, a devida educação da população quanto aos riscos de entrar em áreas onde carrapatos estão presentes. Sendo de extrema importância a realização de novas pesquisas com estudos mais aprofundados, para que se possa fazer um maior levantamento de dados de coleta, contando com uma maior sensibilização dos profissionais da saúde para este agravo. 


\section{REFERÊNCIAS.}

ALMEIDA, R, F; GARCIA M, V, CUNHA, R, C; MATIAS, J, ARAUJO e Silva, E et al. Ixodid fauna and zoonotic agents in ticks from dogs: first report of Rickettsia rickettsii in Rhipicephalus sanguineus in the state of Mato Grosso do Sul, midwestern Brazil. Exp Appl Acarol. 2013;60(1):63-72.

ARRAIS, R, C. Ocorrência de patógenos Transmitidos por carrapatos (Anaplasma ssp, Babesia ssp, Erlichia ssp, Hepatozoon ssp e Rickettsia ssp) em lobo guará (Chysosyoun brachyurus) e cães dométicos da região do parque Nacional da Serra da Canastra. São Paulo, 2013. (Dissertação apresentada ao Programa de Pós-graduação em Epidemiologia Experimental Aplicada ás Zoonoses da faculdade de Medicina Veterinária e Zootecnia da Universidade de São Paulo).

ARAÚJO, P.M.; NAVARRO, M.B.M.A.; CARDOSO, T.D.A. Febre Maculosa no Brasil: estudo da mortalidade para a vigilância epidemiológica. Cad. de Saúde Coletiva, 2015, Rio de Janeiro, 23(4): 354-361.

BRASIL, MINISTÉRIO DA SAÚDE. Guia de Vigilância em Saúde. Vol. Único. Brasília, 2015.

BRASIL, MINISTÉRIO DA SAÚDE. Guia de Vigilância Epidemiológica. Brasília, 2005.

CHAREONVIRIYAPHAP, T et al. Dual exposure of Rickettsia typhi and Orientia tsutsugamushi in the field-collected Rattus rodents from Thailand. Journal of Vector Ecology. Tailandia, jun. 2014. Disponível em: http://web.b.ebscohost.com/ehost/pdfviewer/pdfviewer?sid=6cf7b0aa-67894da0-bd8b-db491d5c2399\%40sessionmgr105\&vid=0\&hid=125

COSTA, A, P et al. A serological and moleculer survey of Babesia vogeli, Erlichia canis and Rickettsia spp. Among dogs in the state of Maranhão, northestern Brazil. Resvista Braz. J. Vet. Parasitol, Jaboticabal, v. 24, n. 1, p. 28-35, janmar. 2015. Disponível em: http://www.scielo.br/pdf/rbpv/v24n1/1984-2961-rbpv24-1-28.pdf 
COSTA-JUNIOR et al. Use of a Real Time PCR for derecting subspecies of Babesia canis. Vet Parasitol. 2012, v. 188, n. 2, p. 160-163. Disponível em: http://dx.doi.org/10.1016/j.vetpar.2012.03.015. PMid:22516643

COUTO, D, V et al. Brazilian Spotted Fever: the importance of dermatological signs for early diagnosis. An Bras Dermatol. 2015, v. 90, n. 2, p. 248-250. Disponível em: http://www.ncbi.nlm.nih.gov/pmc/articles/PMC4371677/

DANTAS-TORRES, F. Ticks on domestic animals in Pernambuco, Northeastern Brazil. Revista Brasileira de Parasitologia Veterinária. Jaboticabal. v. 18, n. 3 , p. 22-28, jul-set. 2009.

DEL FIOL FS.; Junqueira FM.; Rocha MCP.; Toledo MI.; Filho SB. A febre maculosa brasileira. Rev Pan de Salud Púb 2010 jun; 27(6):461-6.

DEMONER, L, C et al. Investigation of tick vectors of Hepatozoon canis in Brazil. Ticks Tick Borne Dis. 2013, v. 4, n. 3, p. 542-546. Disponível em: http://dx.doi.org/10.1016/j.ttbdis.2013.07.006. PMid:24209494

ESTRADA, Dora Amparo et al. Detecção de riquétsias em carrapatos do gênero Amblyomma (Acari: Ixodidae) coletados em parque urbano do município de Campinas, SP. Rev. Soc. Bras. Med. Trop. Uberaba, v. 39, n. 1, p. 68-71, Feb. 2006 .

FORTES, F.S; BIONDO, A.W; MOLENTO, M.B. Febre Maculosa Brasileira em cães. Semina: Ciências Agrárias, Londrina, v. 32, n. 1, p. 339-354, jan./mar. 2011.

GAZI, M et al. Discovery of a Protective Rickettsia aprowazeki Antigen Recognized by CD8+ T Cells, RP884, Using an In Vivo Screenig Platform. Plos One. v. 8, n. 10, pag. 1-10, out, 2013. Disponível em: http://web.b.ebscohost.com/ehost/pdfviewer/pdfviewer?sid=2974ddb2-889a49ed-bb2a-a4159e705598\%40sessionmgr104\&vid=1\&hid=125 
GOMES, Ricardo et al. Resposta immune-humoral de búfalos contra Anaplasma marginale. Brasil, 2008. Disponível em: http://dx.doi.org/10.1590/S1984$\underline{29612008000200003}$

GRISI, L. et al. Impacto econômico das principais ectoparasitoses em Bovinos no Brasil. A Hora Veterinária, v. 21, n. 125, p. 8-10, 2002.

KANTOS, M. et al. Prevalence and seasonal abundance of ticks on dogs and the role of Rhipicephalus sanguineus in transmitting Babesia species in Maidugiri, North- Eastern Nigeria. Veterinary Word. Nigéria, v. 7, p. 119-124, march. V. 7, n. 7. Jan. 2014.

KRAWCZAK, F, S et al. Rickettsial infection in Amblyomma cajennense ticks and capybaras (Hydrochoerus hydrochaeris) in a Brazilian spotted fever-endemic area. Parasites \& Vectors. 2014

LABRUNA, M.B. Biologia-Ecologia de Rhipicephalus sanguineus (Acari: Ixodidae). Revista Brasileira de Parasitologia Veterinária, v.13, p.123-124, 2004.

LABRUNA, M.B; PEREIRA, M.C. Carrapatos em cães no Brasil. Clínica Veterinária, v.30, p.24-32, 2001

LABRUNA, M,B, et al. Detection of a spotted fever group Rickettsia in the tick Haemaphysalis juxtakochi in Rondônia, Brazil. Vet Parasitol. 2005;127(2):16974.

LEMOS, E.R.S.; ROZENTAL, T.; MONTEIRO, K.J.L. Diagnóstico Diferencial entre Febre Maculosa Brasileira e o Dengue no contexto das doenças febris agudas. Rev Patol Trop Vol. 43 (3): 241-250. jul.-set. 2014.

LUZ, H, B. et al. Carrapatos parasitando cães em uma área insular do estado do Rio de Janeiro, RJ, Brasil. Revista Brasileira de Medicina Veterinária. Rio de Janeiro. N. 36. vol 4. p. 437-442, out/dez. 2014

MELLES, H.H.B; COLOMBO, S; SILVA, M.V. Febre Maculosa: isolamento de Rickettsia em amostra de biópsia de pele. Rev. Inst. Med. Trop. São Paulo, 34(1); 37-41, jan/fev, 1992. 
MILAGRES, B. S; PADILHA, A. F.; Barcelos, R; GUIMARAES, G.; MONTANDON, C. ; PENA, D. C.; NIERI, F. ; SILVEIRA, I.; PACHECO, R. C.; LABRUNA, M. B.; BOUYER, D.; FREITAS, R. N.; Mafra, CL; WALKER, D. H.; GALVAO, M. A. M. . Investigation of Rickettsia in Synanthropic and Domestic Animals and in their Host from two areas of low endemicity for Brazilian Spotted Fever, in the east Region osf Minas Gerais state, Brazil. The American Journal of Tropical Medicine and Hygiene, v. 83, p. 1305-1307, 2010.

MILAGRES, B. S; PADILHA, A. F.; MONTANDON, C.; PACHECO, R. C.; LABRUNA, M. B.; FREITAS, R. N.; MAFRA, CL; WALKER, D. H.; GALVAO, M. A. M. Spotted fever group Rickettsia in small rodents from areas of low endemicity for Brazilian spotted fever in the eastern region of Minas Gerais state, Brazil. The American Journal of Tropical Medicine and Hygiene, v.88, p.937 939, 2013

MOLITERNO, F.M. Febre Maculosa Brasileira: aspectos epidemiológicos e laboratoriais dos casos ocorridos no estado do Rio de Janeiro no período de janeiro de 2014 a dezembro de 2008. FIOCRUZ. Mestrado em Medicina Tropical, Rio de Janeiro, 2009.

NICHOLSON, W, L et al. The increasing recognition of rickettsial pathogens in dogs and people. Rev. Trends Parasitol, v. 26, n. 4, p. 205-212. Abr, 2010. Disponível em: http://www.ncbi.nlm.nih.gov/pubmed/20207197

NOGUERAS, M, M et al. Molecular Detection of Rickettsia typhi in Cats and Fleas. Plos One. v. 8, n. 8, p. 1-8, ago, 2013. Disponível em: http://web.b.ebscohost.com/ehost/pdfviewer/pdfviewer?sid=8f68d99b-01b0481b-89f6-c7584a93a052\%40sessionmgr 102\&vid=0\&hid=125

NOGUEIRA, A.H.C. et al. Febre Maculosa. Pesquisa \& Tecnologia, vol. 2, n.2, Jul-Dez 2005.

OLIVEIRA, S, V; PEREIRA S, V, C; SILVA, P, M, R, B; PEREIRA J, M; GOMES $\mathrm{V}$; AMORIN, $M$ et al. Vigilância de ambientes da febre maculosa brasileira e 
outras riquetsioses: a etapa inicial de uma proposta para a formação de rede. Rev Pan-Amaz Saude. 2015;6(3):67-71.

OLIVEIRA, S.V et al. An update on the epidemiological situation of spotted fever in Brazil. Journal of Venomous Animals and Toxins including Tropical Diseases (2016) 22:22.

OTRANTO, D et al D, Application of $10 \%$ imidacloprid $/ 50 \%$ permethrin to prevent Ehrlichia canis exposure in dogs under natural conditions. Resvi. Vet Parasitol, v. 3-4, n. 153, p. 320-328, Mai, 2008.

PINTER, et al. Febre maculosa brasileira. Bol Epidemiol Paulista. 2011;8(1):331.

RAMOS, $R$ et al. Molecular survey and genetic characterization of tick-borne pathogens in dogs in metropolitan Recife (north-eastern Brazil). Parasitol Res 2010; v.107, n. 5, p. 1115-1120. Disponível em: http://dx.doi.org/10.1007/s00436-010-1979-7PMid:20680344

RIKIHISA, Y. Anaplasma Phagocytophilum and Erlichia chaffeesis: subversive manipators of host cells. Nature reviews Microbiology. v. 8, n. 8, p. 328- 339, Mai, 2010.2 Disponível em: http://www.nature.com/search?order=relevance\&q=Ehrlichia\%20canis

SILVA, G, C et al. Occurrence of Ehrrlichia canis and Anaplasma platys in household dogs from northern Parana. Revista Brasileira de Parasitologia Veterinária. 2012, v. 21, n. 4, p. 379-385. Disponível em: http://dx.doi.org/10.1590/S1984-29612012005000009. PMid:23207986

SILVA et al. Febre maculosa: uma análise epidemiológica dos registros do sistema de vigilância do Brasil. Rev. Scientia Plena 10, 047501, 2014.

SOUZA, E, J. et al. Ação do fungo Beauveria bassiana associado a gel polimerizado de celulose no controle do carrapato Anocentro nitens em testes 
de campo. Resvista Brasileira de Medicina Veterinária e Zootécnica. Rio de Janeiro, v. 16, n. 1, p. 163-169, out. 2009.

SPOLIDORIO, M, G et all. Molecular detection of Hepatozon canis and Babesia canis vogeli in domestic dogs from Cuiaba, Brasil. Revista Brasileira de

Parasitologia Veterinária. 2011, v. 20, n. 3, p. 253-255, disponível em:

http://dx.doi.org/10.1590/S1984-29612011000300015.PMid:21961759

STANNECK D,et al. The synergistic action and release kinetics of $10 \%$ imidacloprid and $4.5 \%$ flumethrin in collars applied for ectoparasite control in dogs and cats. Revis. Parasit Vectors, v.5, n. 73, p. 1-4. Abr, 2012. Disponível em: http://www.ncbi.nlm.nih.gov/pubmed/22498105

STANNECK, D; FOURIE, J, J. Imidacloprid $10 \%$ / Flumethrin $4.5 \%$ Collars (Seresto®, Bayer) Successfully Prevent Long-Term Transmission of Ehrlichia canis by Infected Rhipicephalus sanguineus Ticks to Dogs. Parasitol Res, n. 112, p. 21-32. Ago, 2013.

VRANJAC, A. Varicela, difteria e febre maculosa brasileira: aspectos epidemiológicos no Estado de São Paulo. Rev. Saúde Pública 2003;37(6):81720

VIEIRA, A, M, L. et al. Manual de vigilância acarologia. Disponível em: http://www.saude.sp.gov.br/resources/sucen/homepage/downloads/arquivosde-febre-macul osa/manual vig acarologica.pdf

VIEIRA, T, S, W, J et al. Serosurvery of tick-borne pathogens in dogs from urban and rural áreas from Parana State, Brazil. Revista brasileira de Parasitoogia Veterinária. 2013, v. 22, n. 1, p. 104-109. Disponível em: http://dx.doi.org/10.1590/S1984-29612013000100019. PMid:24252955

WOOD, D, O et al. Establishment of a Replicating Plasmid in Rickettsia prowazekii. Revista Plos One. v. 7, n. 4, p. 1-6, Abri, 2012. Disponível em: http://web.b.ebscohost.com/ehost/pdfviewer/pdfviewer?sid=4d8e0e16-77f34db8-8fb7-c445b3ec0305\%40sessionmgr103\&vid=1\&hid=125. 